\title{
AN ALTERNATIVE APPROACH FOR SOLVING THE SPACE INTERSECTIONS PROBLEM IN CLOSE RANGE PHOTOGRAMMETRY
}

\author{
Abo El- Hassan M.Rahil
}

\begin{abstract}
There are different techniques, that can be used for monitoring building deformations, each is designed for a certain purpose and also depending on many parameters, such as the shape of the construction, the quantity of the deformation, the needed time to collect the necessary measurement and the required accuracy. These techniques can be generally classified into surveying and non surveying techniques. The surveying techniques include conventional geodetic techniques and close range photogrammetry. This paper proposes and discuses a more simple alternative approach for the problem of the space intersection in close range photogrammetry, as applied to structure deformation measuring.

In this research, a test field was used, for experimental determination of the accuracy of the results obtained from the proposed approach, and of the conventional techniques frequently used in close range photogrammetry . The accuracy obtained in this study, was determined by comparing the coordinates in each technique with the original check points coordinate of the test field.

The aim of the research reported in this paper, is the study of durability of a more simple alternative approach for solving the space intersection problem in close range photogrammetry as applied to monitoring structure deformation, through its comparison with the corresponding conventional techniques.
\end{abstract}

Key word : Close-range photogrammetry - space intersection.

Manuscript received from Dr. ABO EL-HASSAN M. RAHIL on : 21/3/2000 Accepted on : $7 / 6 / 2000$

Engineering Research Bulletin, Vol 23,No 3, 2000 Minufiya University, Faculty of Engineering, Shebien EI-Kom, Egypt, ISSN 1110-1180 


\section{Introduction}

Construction surveying plays an important role in the process of erecting a structure. Surveying operation are necessary before construction, for planning and designing purposes, then during construction the surveying is necessary to ensure the layout of the structure and guide the construction process and after the structure is finished, surveying is used to monitor the structural deformations. he use of photogrammetric techniques, specially close-range photogrammetry, in construction. surveys have been reported earlier by Abdel Aziz 1979, Clarke,T.,1990 and others. The close range photogrammetry provides information at a very large number of points at the same time.. This advantage is very essential, in case of structures, having rapid movements or deformations. This is the case, since the traditional other surveying techniques take more time to collect the necessary measurements at a certain time, during which the different monitoring defined targets could have gained a quite movement, not coincide with the measurement instance. The conventional geodetic methods provide information on movement at only a little number of targets on the object. By using the close range photogrammetry, a permanent record can be taken of a very large number of monitoring targets points.

In close range photogrammetry there are three different techniques in locating control:

The first technique is mostly convenient in photogrammetric applications, by fixing all the control in the object space. In this method, the camera position and orientation is determined by analytical photogrammetry.

The second technique is done by fixing the camera position and orientation with respect to the object space coordinate system. In close range photogrammetry, the stereo metric camera is convenient on account of its fixed base and relative orientation. It is quite appropriate to use the stereo metric camera base and the local vertical to define the object space coordinate system.

This paper, however, is introducing the use of a more simple alternative approach for the second technique in establishing control.

The third technique combine between the first and the second technique, where part of the control is forced on the camera and part is located in the object space. The second technique in establishing control is realized most conveniently by using stereo metric camera, which consists of two identical cameras mounted rigidly at the ends of a fixed base, where two horizontal overlapping photographs are taken.

This technique is not used in this study for the following reasons:

-The stereo metric cameras which are required for photography are very expensive, and generally not available, specially in the development countries.

-The stereo metric cameras have fixed base lengths. This means that, the photogrammetrist have no chance to choose the base high ratios. 
Because their bases are relatively short, stereo metric cameras can attain strong base height ratios, only when objects being photographed are rather close range. For better heights ranges, stereo pairs must be obtained by exposing single photographs at the ends of a measured base line, using single camera.

-One needs a minimum of one vertical control point on the photographed object, to determine the elevation of the exposure station. For all of the above reasons, a more simple alternative approach has been suggested in this research.

The advantages of this approach are as follows:

-Using single camera instead of stereo metric camera, to obtain stereo pairs, by exposing single photos at the ends of a measured base line.

-Choosing the suitable base-depth ratio, which gives geometric strength;

-There is no geometric problem, when the photographed object lies in one plane;

-The expected accuracy of the object space coordinates is better than that obtained by using the collinearity conditions, as we will see in the discussions;

-Saving the required time for linear measurements and for control points establishments.

\section{THEORETICAL ASPECT}

Three typical configuration system can be considered, (1) the normal case where the left and right camera axes are perpendicular to the base line (BX).(2) Convergent case where the camera axes are arbitrary convergent and (3) Normal-convergent case where normal photography is performed at one station and convergent photography at the other station (see Rahil 97)

As illustrated in Figure ( 1 ), the angle $\Phi_{L}$ and $\Phi_{R}$, the angles subtended by the camera axes with the directions of the perpendiculars to the camera base on the horizontal planes, define the convergence of the left and right cameras, respectively. These two angles of convergence are assumed known as are $\Phi_{I}$ and $\Phi_{R}$.

If $\Phi_{\mathrm{L}}=-\Phi_{\mathrm{R}}$ one obtains a case of symmetrical convergence. In these case the computations become some what less complex and recommended. In this study, we will be dealing with the symmetric convergent case $\left(\Phi_{\mathrm{l}}=\Phi_{\mathrm{R}}\right.$ $=\Phi)$. For the simplicity and convenience work, photos would be arranged so that the horizontal fiducial line in each photo stays horizontal while the vertical fiducial line in each photo remains vertical. 


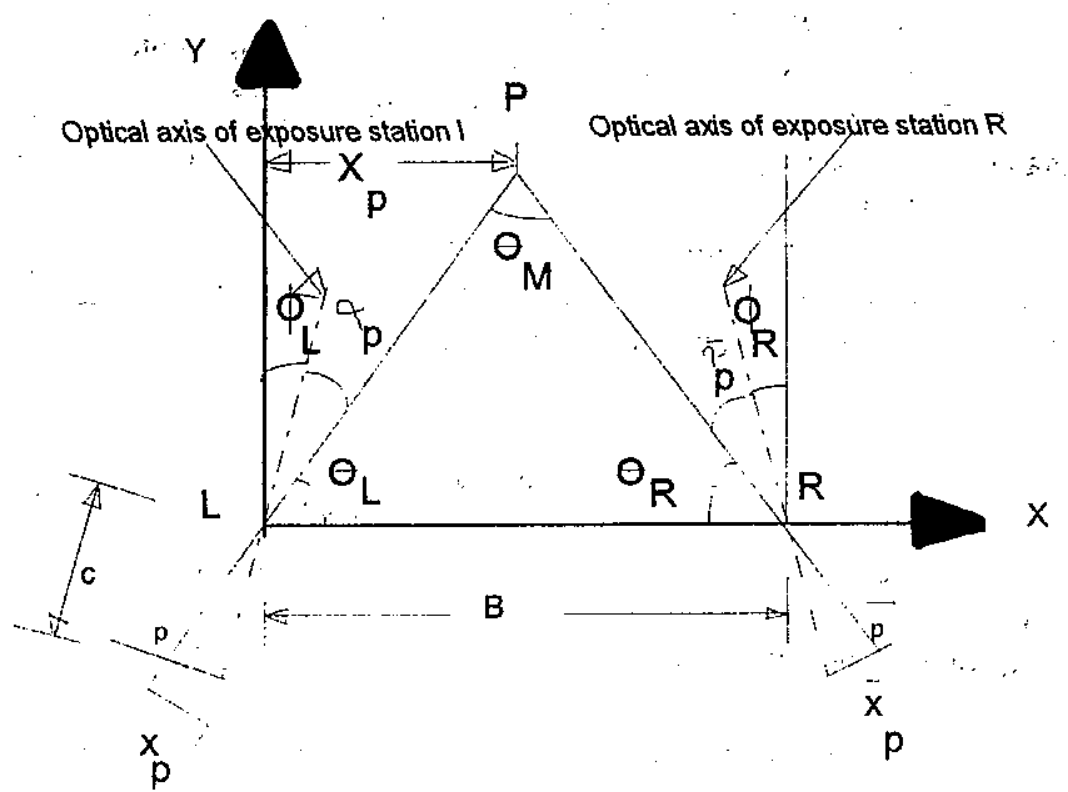

Fig.(1) Horizontal position of points from two horizontal photos.

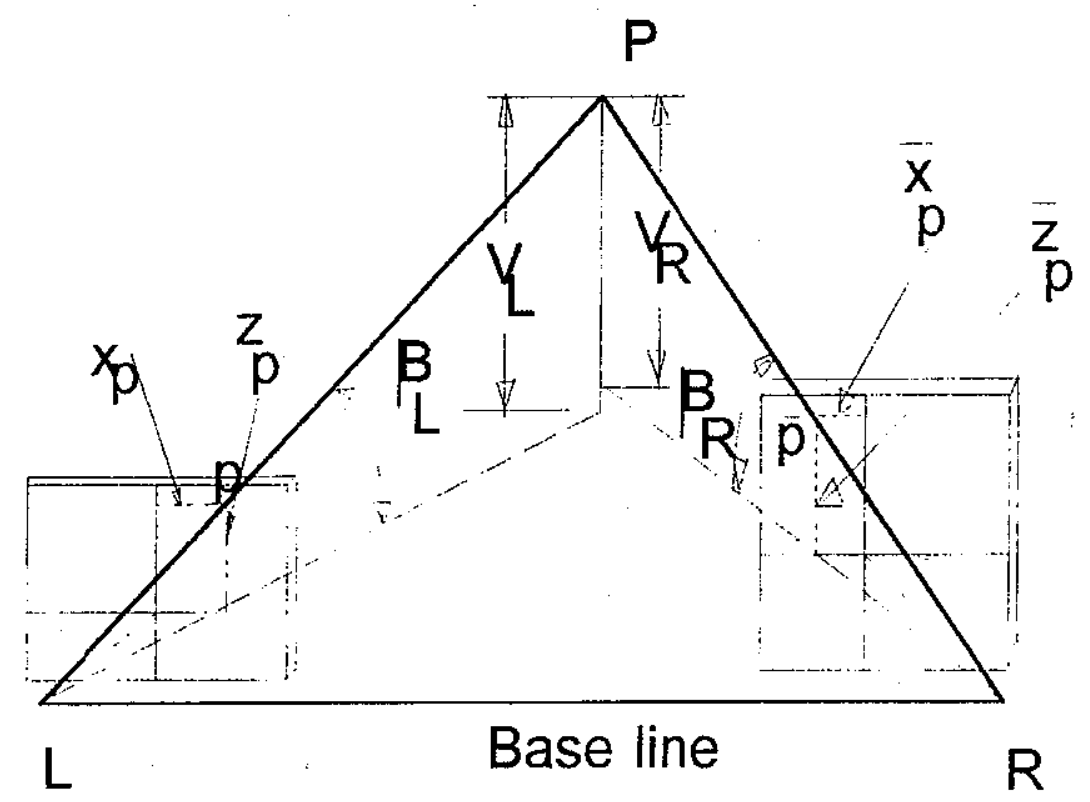

Fig.(2.a) Elevation of points from two horizontal photos. 


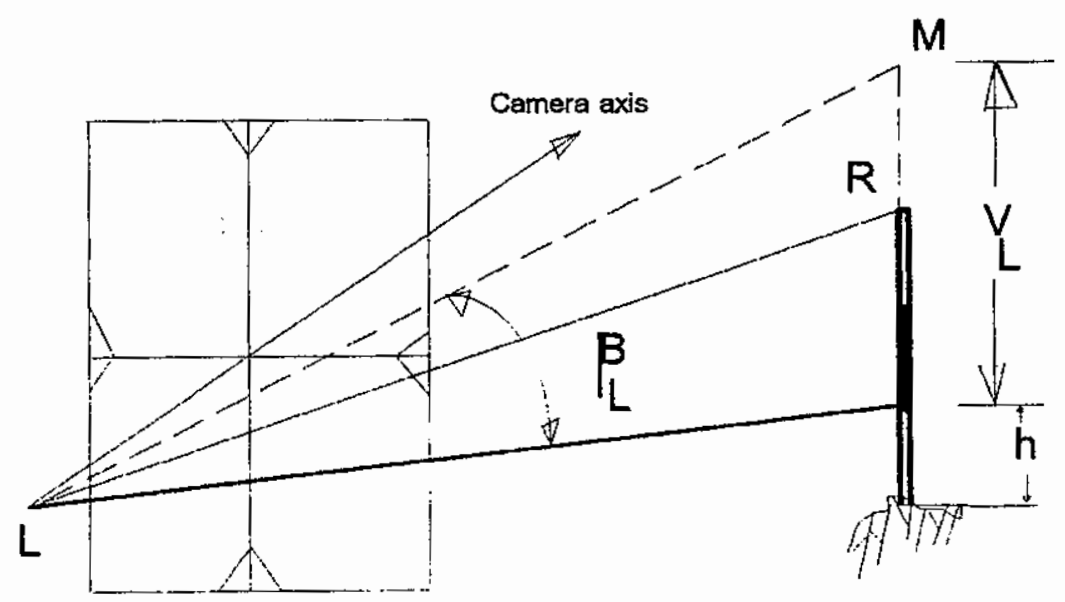

Fig.(2.b) Elevation of points at the left exposure station.

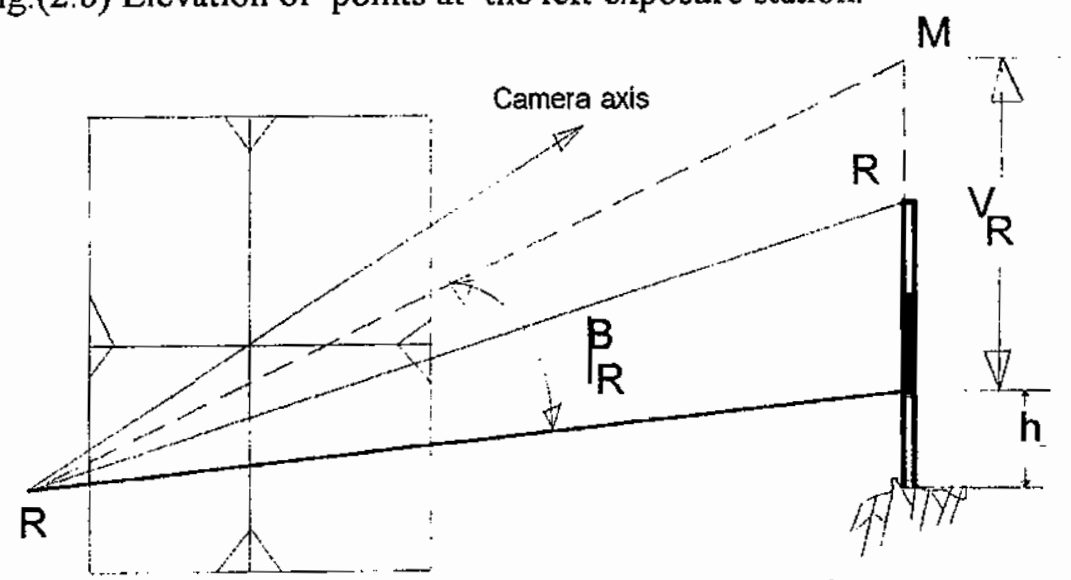

Fig.(2.c) Elevation of points at the right exposure station.

\subsection{RELATIVE ORIENTATIOPN}

By investigating the relative orientation parameters which are required to orient the right photo with respect to the left photo one find that:

-Two orientation parameters of the two photos are known, having zero values; because:

a) The $Z$ - axes of the two photos, which is parallel to the plumb line are parallel $\left(\kappa_{1}=\kappa_{2}=0.0\right)$.

b) Both of the two photo lies on a vertical plane $\left(\omega_{1}=\omega_{2}=0.0\right)$

The translation element along the $Y$-direction $B_{Y}$ has a zero value; because the two exposure stations lie on the $\mathrm{X}$ - axis.

The elevation of the two exposure stations ( left and right) can be calculated by using the following technique :

The philosphy of this technique is based upon photographing of one or more precise levelling staff or special constructed marker poles, ( see 
Collins and Madge 1981) which are fixed at the appropriate places relative to the two exposure stations.

Care is taken in fixing a leveling staff, such that the base plate is at ground, and the staff should be ensure verticality. The effect of photographing leveling is illustrated in Fig.( 2.a-2.c ). The photo coordinates $(x, z)$ from the center of the photography to the bottom of the staff image are recorded. Consider $\beta_{L}$ and $\beta_{R}$ being the vertical angles of inclination between the horizontal plane and the ray from the camera to the object point $P$, on the left and right photos respectively.

$$
\begin{gathered}
\text { Then: } \quad \beta_{\mathrm{L}=\tan ^{-1}\left[\mathrm{z} /\left(\mathrm{x}^{2}+\mathrm{c}^{2}\right)^{0.5}\right]} \\
\beta_{\mathrm{R}}=\tan ^{-1}\left[\mathrm{z}^{z} /\left(\mathrm{x}^{\mathrm{L} 2}+\mathrm{c}^{2}\right)^{0.5}\right]
\end{gathered}
$$

where:

$\mathrm{x}$ is the measured $\mathrm{x}$-dimension (coordinate) from the center of the photo to the image of the staff at the left station

$z$ is the measured $x$-dimension (coordinate) from the center of the photo to the image of the staff at the left station

$\mathrm{x}^{2}$ is the measured $\mathrm{x}$-dimension (coordinate) from the center of the photo to the image of the staff at the left station

$z^{\dot{Z}}$ is the measured $x$-dimension (coordinate) from the center of the photo to the image of the staff at the left station

According to Figure .(2.b) and Figure (2.c ), one can determine the difference in elevation between the camera axis at the left and right camera stations $\left(V_{L}\right.$ and $\left.V_{R}\right)$ respectively. From the photo coordinate of the lower part of the staff $(x, z)$, together with the calculated horizontal distance between the exposure stations and the vertical staff, the difference in elevation $\left(V_{L}\right.$ and $\left.V_{R}\right)$ between the camera axis ( left and right respectively ) , and the lower edge of the staff graduation, can be calculated using the following equation:

$$
\begin{aligned}
& V_{L}=D_{L} \tan \left(\beta_{L}\right) \\
& V_{R}=D_{R} \tan \left(\beta_{R}\right)
\end{aligned}
$$

Where:

$\mathrm{V}_{\mathrm{L}}$ : is the difference in elevation between the exposure station and the lower edge of the staff graduation

$V_{R}$ : is the difference in elevation between the exposure station and the lower edge of the staff graduation

$D_{\mathrm{L}}$, is the horizontal distance from the left camera st to the levelling staff.

$D_{R}$ is the horizontal distance from the right camera st. to the levelling staff.

The exposure stations elevation can be obtained using the following equations :

$$
\begin{aligned}
& E_{1} \cdot V_{1} \cdot h \\
& E_{K} \cdot V_{R}+h
\end{aligned}
$$

Where $E_{\mathrm{I}}$. is the elevation of the exposure station at the left station

$E_{R}$ is the elevation of the exposure station at the right 
$h$ is the elevation of the lower edge of the staff graduation

If more than one vertical staff is available, the average value of exposure stations elevation ( left and right respectively) can be obtained.

\subsection{THE OBJECT SPACE COORDINATE}

A point $(\mathrm{P})$ on object is defined in terms of 3-D coordinates, $\mathrm{X}, \mathrm{Y}, \mathrm{Z}$ while the corresponding points in the photos are in terms of their photocoordinates, $x, z$ for point $p$ on the left photos and $x^{-}, z^{-}$for point $\mathrm{p}^{-}$on the right photos. Referred to Fig.(1), consider the horizontal distance of a ground point $P$ from the left exposure station, $L P=D_{L}$. The horizontal distance of the ground point $P$ from the right exposure station, $R P=D_{R}$.

Consider $\alpha_{p}$ and $\alpha_{p}{ }^{-}$being the horizontal angle between the optical axis $\left(C A_{L} \& C A_{R}\right)$ and the ray from the camera to object point $P$ on the left and right photo respectively.

Furthermore, $a_{p}=\arctan (x / c)$ and $\alpha_{p}^{\circ}=\arctan \left(x^{?} / c\right)$

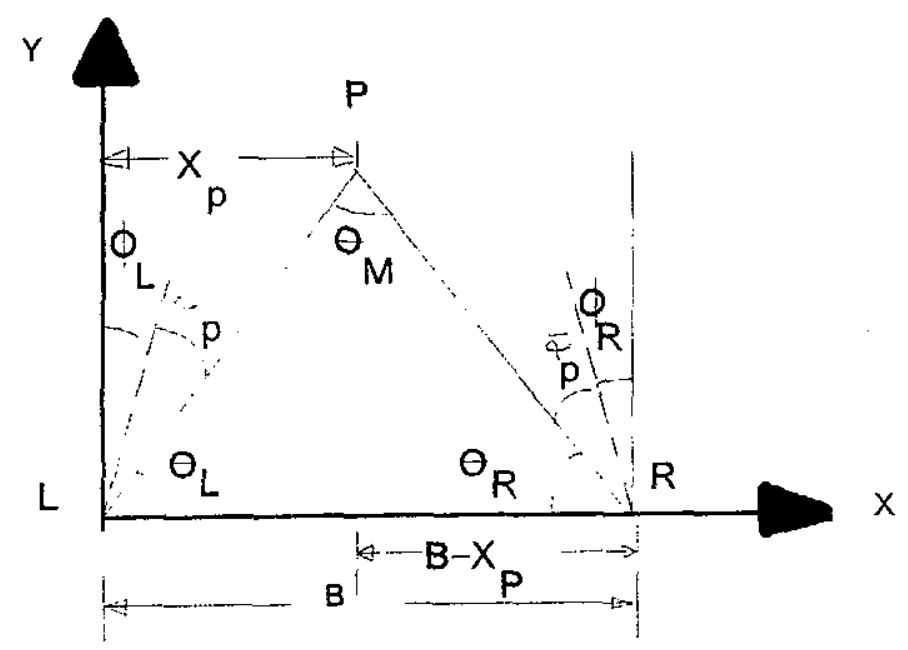

Fig.(3) Horizontal position of points from two horizontal photos.

$$
\begin{gathered}
\delta_{\mathrm{L}}=90-\Phi_{\mathrm{I}}, \delta_{\mathrm{R}}=90-\Phi_{\mathrm{R}} \\
\theta_{\mathrm{l}}=\delta_{\mathrm{L}}-\alpha_{\mathrm{I}}, \quad \theta_{\mathrm{R}}=\delta_{\mathrm{R}}-\alpha_{\mathrm{R}} \\
\theta_{\mathrm{L}}=90-\Phi_{\mathrm{L}}-\alpha_{\mathrm{L}} \theta_{\mathrm{R}}=90-\Phi_{\mathrm{R}}-\alpha_{\mathrm{R}} \\
\theta_{\mathrm{M}}=180-\left(\theta_{\mathrm{L}}+\hat{\theta}_{\mathrm{R}}\right)
\end{gathered}
$$

Consider $\theta_{\mathrm{L}}$ and $\theta_{\mathrm{R}}$ being the horizontal angles between the target $(\mathrm{P})$ and the base line at the left and right exposure station respectively,

$$
\text { Then } \theta_{\mathrm{M}}=180-\left(\theta_{\mathrm{I}}+\theta_{\mathrm{R}}\right)
$$

Also, from sine rules in triangle $L P R$,

$$
\frac{D_{L}}{\operatorname{Sin} \theta_{R}}=\frac{B}{\operatorname{Sin} \theta_{3}}
$$




$$
\begin{aligned}
& \text { i.e. } D_{L}=\frac{B \operatorname{Sin} \theta_{R}}{\operatorname{Sin} \theta_{M}} \\
& \text { and also } \frac{D_{R}}{\operatorname{Sin} \theta_{L}}=\frac{B}{\operatorname{Sin} \theta_{M}} \\
& \text { i.e. } D_{R}=\frac{B \operatorname{Sin} \theta_{L}}{\operatorname{Sin} \theta_{M}}
\end{aligned}
$$

These give the object space coordinates:

$$
\begin{aligned}
& X_{\mathrm{P}}=\mathrm{D}_{\mathrm{L}} * \operatorname{Cos} \theta_{\mathrm{L}} \\
& \mathrm{Y}_{\mathrm{P}}=\mathrm{D}_{\mathrm{L}} * \operatorname{Sin} \theta_{\mathrm{L}} \\
& \mathrm{Z}_{\mathrm{P}}=\mathrm{E}_{\mathrm{L} \text { (average) }}+\mathrm{D}_{\mathrm{L}} * \tan \beta_{\mathrm{I}}
\end{aligned}
$$

\subsection{THE DETERMINTION OF THE BSE LINE ( B )}

The length of the base line can be obtained as follows:

-Determine the ground coordinate of the two ends of the known line (L) by using any assumption value for (B) such as B

Compute the ratio $(R)$ between the true length of the known line $(L)$ and the calculated length of the same known line $(\mathrm{L})$, which was calculated from the ground coordinates.

-Compute the correct value of the base line (B) a follows:

$$
\text { Ratio }(R)=\frac{\text { True length of the known line }(L)}{\text { Computed length of the known line }\left(L^{-}\right)}
$$

$$
\text { The correct value }(\mathrm{B})=\mathrm{B}^{-} *(\mathrm{R})
$$

\section{CHECK COMPUTATION OF THE OBJECT SPACE COORDINATES}

According to figure (3), the object space coordinates can be determined as a check computation using the following equations:

$$
\begin{aligned}
& X_{\mathrm{l}^{\prime}}-\mathrm{B}-\left(\mathrm{D}_{\mathrm{R}}{ }^{*} \operatorname{Cos} \theta_{\mathrm{R}}\right) \\
& \mathrm{Y}_{\mathrm{P}}=\mathrm{D}_{\mathrm{R}}{ }^{*} \operatorname{Sin} \theta_{\mathrm{R}}
\end{aligned}
$$




$$
\mathrm{Z}_{\mathrm{P}}=\mathrm{E}_{\mathrm{R} \text { (average) }}+\mathrm{D}_{\mathrm{R}} * \tan \beta_{\mathrm{R}}
$$

\section{THE EXPERMMENTAL WORK}

In this research, a test field has been successfully used for experimental work. The test field was photographed with the metric UMK 10/1318 from Zeis Jena. The elevation view of the test field is shown in figure $(4$.

Two stereo pairs were so arranged, that they were on the same base and also one base-to object distance ratio is used. The first stereo pair is performed horizontal in a symmetrical convergent imaging with $29^{\circ}$ convergent angle, and the second stereo pair is established also horizontal in a symmetrical convergent imaging with $43^{\circ}$ convergent angle. In the photography two precise leveling staff in a vertical position and a subtence bar were used. The leveling staff and the subtence bar are 2 meters long and they were lying in front of the test field. All the photographs were measured with the stereo comparator Techochart-D from Carl Zeis Jena. The photo coordinate were measured with $\pm 5 \mu \mathrm{m}$ accuracy.

\subsection{THE LOCAL COORDINATE SYSTEM}

The local coordinate system is established by defining the $\mathrm{X}, \mathrm{Y}, \mathrm{Z}$-axis. The directions of the $X, Y, Z$ - axes are as follows: The $X$ and $Y$ axis are laying on a horizontal plane and the $Z$ axis is parallel to the plumb line (see Fig.2). As in Fig.(-), the local coordinate system is adopted with origin at the left station $\left(\mathrm{st}_{\mathrm{l}}\right)$ and with the $\mathrm{X}$-axis coincident with the base line $\left(\mathrm{B}_{\mathrm{X}}\right)$.

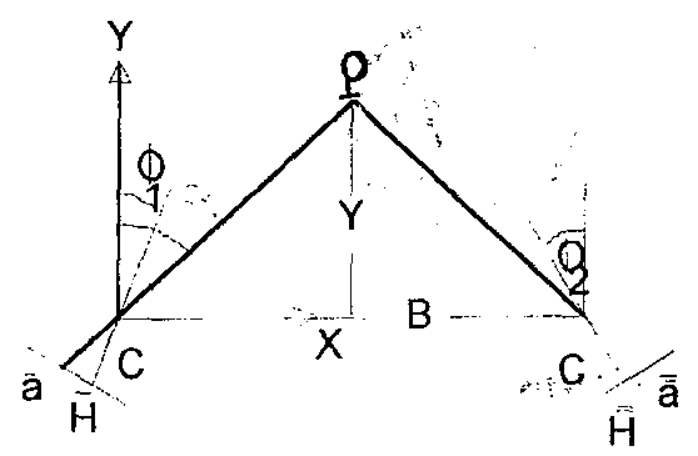

FIG.(4) The local coordinate system.

\subsection{TEST FIELD}

At the Faculty of Engineering Shebin El-Kom, there is one reference point network, this reference point is a vertical plane formed test wall. The reference point network consists of 24 fixed black and white circular shaped Figure (6) The cobrdinates of the check and control points were cmputed 
using the intersection method. The three dimensional vertical test field ( 15 $\mathrm{m}$ by $11 \mathrm{~m}$ by $6 \mathrm{~m}$ ) has been characterized by the following:

RMS error:0.2 $\mathrm{mm}$ for X-axis, $0.2 \mathrm{~mm}$ for the $\mathrm{Y}$-axis and $0.1 \mathrm{~mm}$ for the $\mathrm{Z}$ axis.

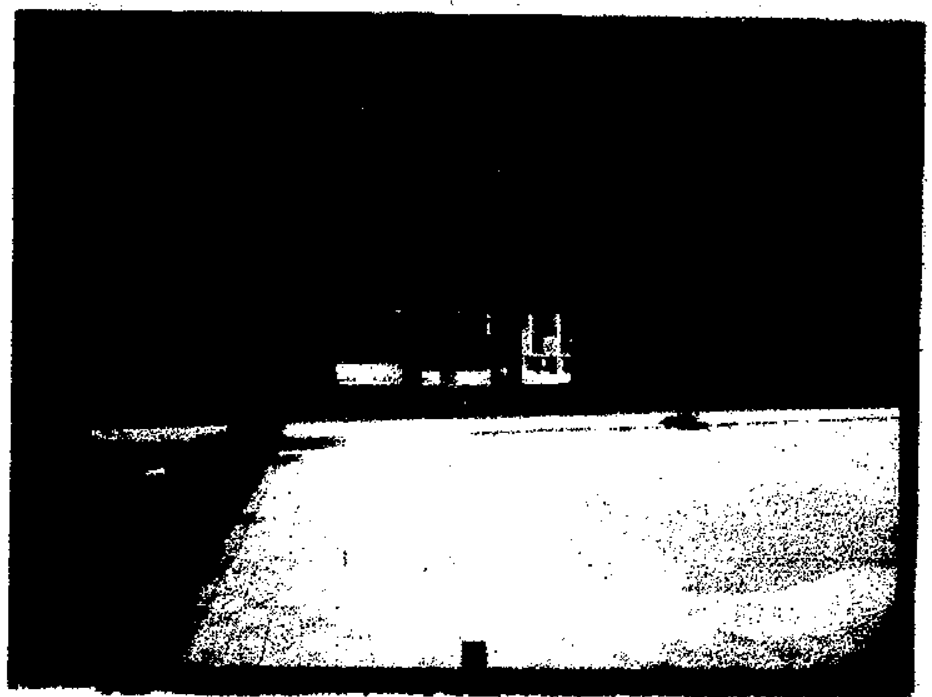

Fig.(5) The test field and the reference points network by using the metric camera UMK $10 / 118$

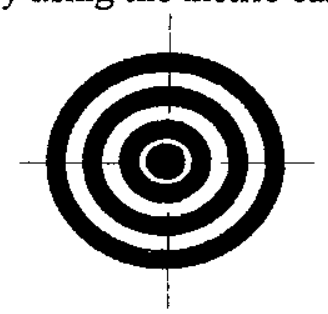

FiG.( 6 ) The Target.

\section{DATA REDUCTION}

In this work, the data reduction have been done with two different analytical approaches to determine the ground coordinates of points of interest : the conventional method and the suggested approach

\subsection{THE CONVENTIONAL APPROACH}

In this approach, the mathematical model for the terrestrial photogrammetry is based on the collinearity equations. The analytical restitution was performed using bundle adjustment. For this purpose, 6 
control points have been used, to determine the space resection parameters With the knowledge of the space resection parameters of the two photos, the space - intersection can be performed to obtain the ground coordinates of object points .

\subsection{THE PROPOSED APPROACH}

In this approach, no control point have been used. The data reduction procedure consists of :

a) The determination of the horizontal angles $\left(\alpha_{L}\right.$ and $\left.\alpha_{R}\right)$ between the optical axis and the ray from the camera to object point $P$, on the left and right photo respectively;

b) determination of the vertical angles $\left(\beta_{\mathrm{L}}\right.$ and $\left.\beta_{R}\right)$ between the horizontal plane and the ray from the camera to object point $P$, on the left and right photo respectively;

c) Computation of the horizontal angles $\left(\theta_{\mathrm{L}}\right.$ and $\left.\theta_{\mathrm{R}}\right)$ between the object point $\mathrm{P}$, and the base line at the left and right exposure stations respectively;

d) Calculation of the horizontal distances $\left(D_{l}\right.$, and $\left.D_{R}\right)$ between the object point $P$, and the left and right exposure station respectively , and

e) Computation of the coordinates (X,Y and $\mathrm{Z}$ ) of points of interest.

\section{THE COMPARISON OF RESULTS}

In this study, one base-to- object distance ratio is used $(0.7)$, with a convergence of the two camera axes of 29 grades for the first model and 43 grades for the second model.

The resulting accuracy achieved by both approaches is determined by comparing the obtained coordinates from each approach with the reference coordinates of 20 check points, as determined by geodetic techniques, as mentioned before. The comparison of results between the suggested technique and the conventional method is shown in table (1) for the first stereo model and in table (2) for the second stereo model, and in terms of $\mathrm{X}, \mathrm{Y}, \mathrm{Z}$ coordinates differences as will as, their essentially statistical parameters $\left(\mathrm{RMS}_{1}, \mathrm{RMS}_{2}\right)$

From these two tables, it can be seen that, the proposed approach gives more accurate results than the conventional approach, since the former yields a smaller RMS than the later. 
TABLE(1):STATISTICS OF OBTAINED COORDINATE DIFFERENCES FOR THE FIRST MODEL BETWEEN THE CONVENTIONAL AND THE PROPOSED TECHNIQUES AT THE USE CHECK POINTS (IN mm)

\begin{tabular}{|c|c|c|c|c|c|c|}
\hline $\begin{array}{l}\text { Pt. } \\
\text { No }\end{array}$ & \multicolumn{3}{|c|}{$\begin{array}{l}\text { THE PROPOSED } \\
\text { TECHNIQUE }\end{array}$} & \multicolumn{3}{|c|}{$\begin{array}{r}\text { THE CONVENTIONAL } \\
\text { TECHNIQUE }\end{array}$} \\
\hline & $\Delta \mathrm{X}$ & $\Delta Y$ & $\Delta \mathrm{Z}$ & $\Delta \mathrm{X}$ & $\Delta Y$ & $\Delta Z$ \\
\hline 1 & 1.33 & 1.51 & 1.28 & 1.58 & 2.83 & 2,11 \\
\hline 2 & 1.31 & 1.24 & 1.32 & 1.51 & 1.63 & 1.41 \\
\hline 3 & 1.51 & 1.12 & $1 . \overline{33}$ & 1.42 & 1.69 & 1.43 \\
\hline$\overline{4}$ & 1.08 & 1.17 & 0.98 & 1.53 & 1.75 & 1.57 \\
\hline 5 & 1.21 & 1.37 & 1.28 & 1.44 & 2.64 & 1.69 \\
\hline 6 & $1.4 \mathrm{I}$ & 1.52 & 1.341 & 1.85 & 1.65 & 1.89 \\
\hline 7 & 0.98 & 1.14 & 1.42 & 1.92 & 1.38 & 2.10 \\
\hline 8 & 2.01 & 1.21 & 1.23 & 2.05 & 1.87 & 1.53 \\
\hline 9 & 1.62 & 1.17 & 1.13 & 1.83 & 1.84 & 1.72 \\
\hline 10 & 1.23 & 1.09 & 1.12 & 1.78 & 1.81 & 1.63 \\
\hline 11 & 1.28 & 1.11 & 1.26 & 1.45 & 2.19 & 2.10 \\
\hline 12 & 1.09 & 1.13 & 1.38 & 1.72 & 1.83 & 1.61 \\
\hline 13 & 1.51 & 1.62 & 1.16 & 1.82 & 1.65 & 1.74 \\
\hline 14 & 0.98 & 1.39 & 1.06 & 1.43 & 1.87 & 1.83 \\
\hline 15 & 1.1 & $1 . \overline{34}$ & 1.22 & 1.42 & 2.34 & 1.79 \\
\hline 16 & 1.81 & 1.61 & 1.67 & 2.31 & 1.85 & 2.09 \\
\hline 17 & 0,98 & 1.23 & 1.22 & 1.49 & 1.79 & 2.32 \\
\hline 18 & 1.41 & 1.43 & 1.32 & 2.35 & 1.67 & 1.53 \\
\hline 19 & 1.32 & 1.37 & 1.21 & 1.59 & 1.44 & 1.64 \\
\hline 20 & 1.53 & 1.53 & 1.1 & 1.68 & 1.83 & 1.65 \\
\hline RMS1 & 1.36 & 1.37 & 1.3 & 1.73 & 1.90 & 1.79 \\
\hline
\end{tabular}

TABLE(2):STATISTICS OF OBTAINED COORDINATE DIFFERENCES FOR THE SECOND MODEL BETWEEN THE CONVENTIONAL AND THE PROPOSED TECHNIQUES AT THE USE CHECK POINTS (IN mm)

\begin{tabular}{|c|c|c|c|c|c|c|c|}
\hline $\begin{array}{l}\text { Pt. } \\
\text { No }\end{array}$ & \multicolumn{3}{|c|}{$\begin{array}{l}\text { THE PROPOSED } \\
\text { TECHNIQUE }\end{array}$} & \multicolumn{4}{|c|}{$\begin{array}{r}\text { THE CONVEN TIONAL } \\
\text { TECHINIQUE }\end{array}$} \\
\hline & $\Delta \mathrm{X}$ & $\Delta Y$ & $\Delta Z$ & $\Delta \mathrm{X}$ & $\Delta Y$ & & $\Delta z$ \\
\hline I & 1.30 & 1.54 & 1.26 & 1.62 & 2.67 & & 2.01 \\
\hline 2 & 1.38 & 1.22 & 1.40 & 1.59 & 1.81 & & 1.48 \\
\hline 3 & 1.48 & 1.14 & 1.29 & 1.46 & 1.71 & & 1.82 \\
\hline 4 & 1.18 & 1.17 & 1.08 & 1.62 & 1.83 & & 1.74 \\
\hline 5 & 1.24 & 1.21 & 1.36 & 1.53 & 2.71 & & 1.80 \\
\hline 6 & 1.27 & 1.2 & 1.39 & 1.98 & 1.84 & & 1.92 \\
\hline 7 & 1.14 & 114 & 1.51 & 2.04 & 1.67 & & 2,08 \\
\hline 8 & 1.98 & 1.6 & 1.16 & 2.08 & 1.96 & & 1.74 \\
\hline 9 & 1.57 & 1.16 & 1.18 & 1.89 & 1.91 & & 1.84 \\
\hline 10 & 1.28 & 1.19 & 1.14 & 1.82 & 1.88 & & 1.76 \\
\hline 11 & 1.32 & 1.27 & 1.30 & $1 . \overline{62}$ & 2.09 & & 2.12 \\
\hline 12 & 1.14 & 1.21 & $\overline{1.36}$ & 1.78 & 1.90 & & 1.74 \\
\hline 13 & 1.54 & 1.58 & 1.17 & 1.85 & 1.76 & & 1.82 \\
\hline 14 & 1.04 & $1 . \overline{41}$ & 1.12 & 1.48 & 1.92 & & 1.94 \\
\hline 15 & 1.08 & 1.42 & $1.2 \overline{3}$ & 1.52 & 2.28 & & 1.81 \\
\hline 16 & 1.86 & $1.7 \overline{4}$ & 1.58 & 2.30 & 1.94 & & 2.08 \\
\hline 17 & 0,99 & 1.28 & 1.26 & $1 . \overline{58}$ & $1 . \dot{8} 4$ & & 2.31 \\
\hline 18 & 1.38 & 1.42 & 1.38 & 2.29 & 1.74 & & 1.64 \\
\hline 19 & 1.39 & 1.46 & 1.32 & 1.64 & 1.56 & & 1.72 \\
\hline 20 & 1.48 & 1.44 & 1.18 & 1.80 & 1.92 & & 1.82 \\
\hline RMS2 & 1.37 & 135 & 1.29 & 1.79 & 1.97 & & 95 \\
\hline
\end{tabular}




\section{CONCLUSION}

: :

The previous illustration for the proposed technique shows that, this technique need no control points, provides information at a very large number of points at a minimum time, saving the required time for linear measurements and thus minimum effort, time and cost of field surveying works. The results obtained from the proposed technique are more accurate than those obtained from the conventional photogrammetric technique.

Also, the computations in the proposed technique is simple and requires only a small amount of computer memory .

According to the multitude of advantages of the proposed alternative technique, for close rangr photogrammetric operations, besides the obtained high accuracy, make it to be superior for structure deformation monitoring, as compared to other conventional techniques, and hence, it is recommended for such purposes.

\section{REFERENCES}

Abdel-Aziz,Y.,1.,1979, An application of photogrammetric techniques to building construction .Photogrammetric Engineering and Remote Sensing

Abdel- Grawad, A.K. (1994) "The Application of High precise Surveying Technique in Measuring Deformations of Structures" M.Sc. Thesis, Faculty of Engineering, Ain Shams University.

Amin,E.,A (1987)" Deformation measurement by photogrammetry "Ph.D. Thesis, University of London, England.

Behairy, A. M. and Zahran, M.I.,(1990) "Reliability for Close Range Photogrammetry " Proceeding of the First Conference on Civil Eng., Volume 2, Military Technical College.

Carbonnel,M. and Dallas, R.W.,1985 The International Committee for ArchitecturalPhotogrammetry(CIPA) Aims,Achievements,Activities.Photogrammetria,40(2):193-202.

Clarke, T., 1990," The use of optical triangulation for high speed acquisition of cross section or profiles of structures", Phtogrammetric Record, 13,(76),pp. 523-532.

Cooper,M.A., and Robson,S., 1990, “ High precision photogrammetric monitoring of the deformation of a Steel Bridge" Phtogrammetric Record, 13,(76),pp. 505-510.

Ebner . Fristsch and Heipke 1991 Digital photogrammetric systems Wichmann verlag

El-Komy,A. 1989 " Evaluation of two surveying methods for measuring deformation",M.Sc. thesis, cairo University, Cairo. 
El-Hoseny M., 1993 " An Algorithm for high accuracy surveying in engineering structures and industrial sites", Engineering Bulletin, Vol:28,NO.1, Ain Shams University, Cairo.

Frei,A and Scherrer, 1992, "Use of the Global positioning System in Dam deformation and Engineering surveys"; Leica AG.,Herrbrug,Switzerland.

Gosh.S., 1988, "Analytical photogrammetry"Pergman press.,New York.

Karara ,H.,M. 1989 Non - topographic photogrammetry American Society for photogrammetry and remote sensing.

Mofitt,F.H and Mikhail, E. ,1980, "Photogrammetry" Harper\&Row. Publishers, New York.

Rahil,A.M. (1997) "A Comparative Study of Different Configuration Systems in Cose-Range Photogrammetry" Civil Engineering Research Magazine EL-AZhar Univ., Vol.(19),No.5,1997

Von Gelder,..B.H.,. 1994, "Geodetic Control Survey: Lecture Notes", Purdue University, Civil Eng. Dep., West Lafayette, IN., USA

Wester-Ebbinghause,W.,1980 Numerische Verfahren fur die Architekturphotogrammetrie. International Archives of photogrammetry,XXIII (B5):813-823. 


\section{إقتراح حل بديل لمشكلة التقاطع الأمامى في}

التصوير الأرضى ذو الملدى القريب

$$
\text { إدابورالمسن محمد رحيل }
$$

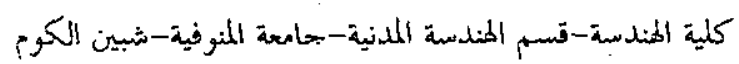

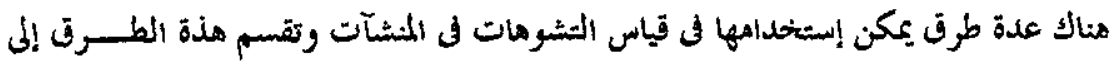

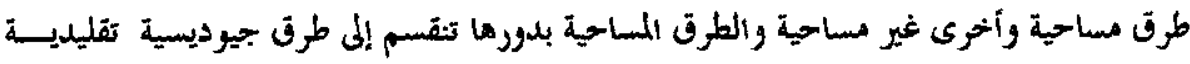

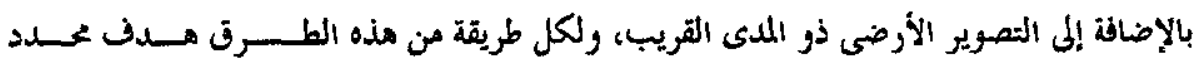

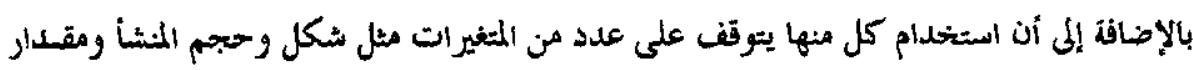

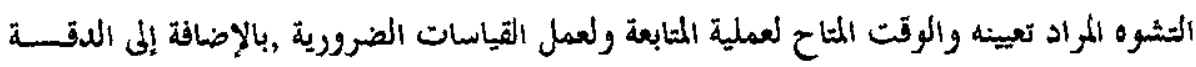

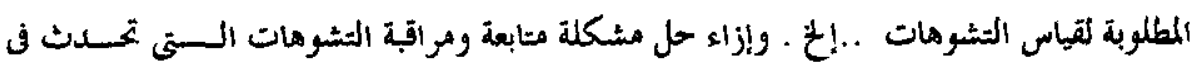

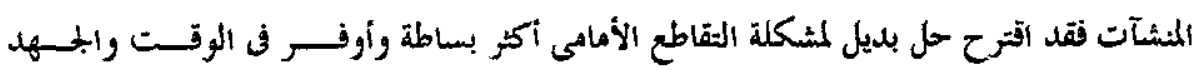

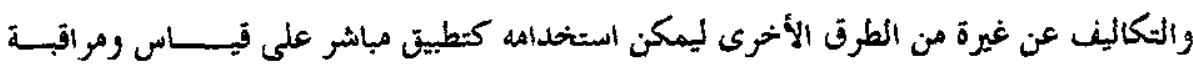

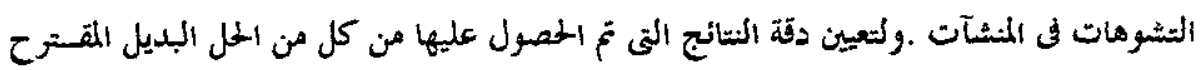

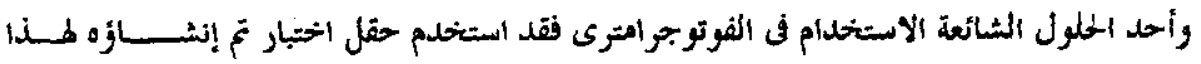

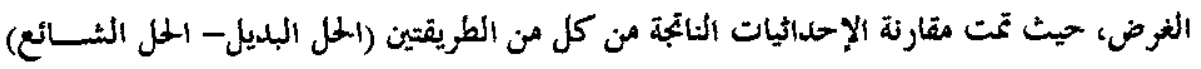
يإسلاثيات نقط التحقيق فل حقل الإنتبار.

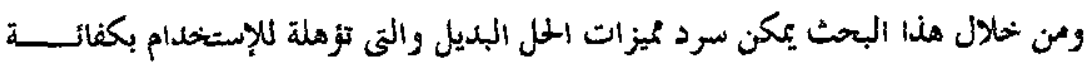

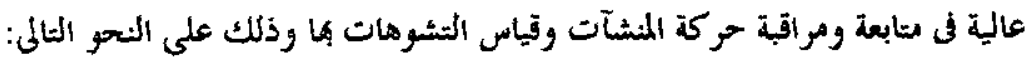

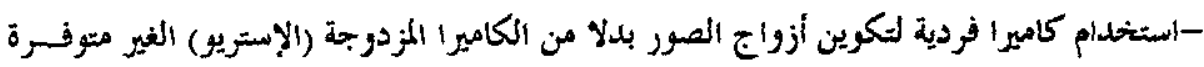
غالبا والغالية الثمن.

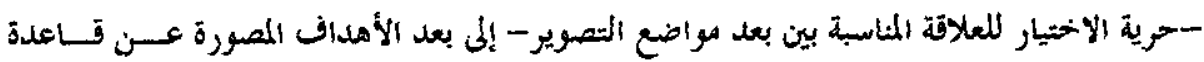

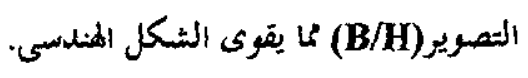

- أمكن من خحلال الحل البديل المقترح التغلب على مشكلة تعبين إحداثيات نقط الأجسام الواقعسة في مستوى واسحل.

- أمكن تحقيق نتائج عالية الدقة بالقارنة بالحل الشائع الاستخدام فل الفوتو جوا أمترى.

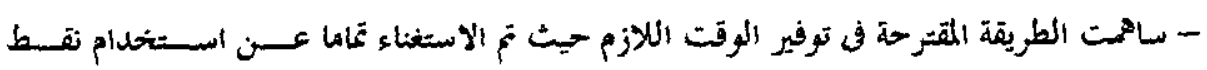

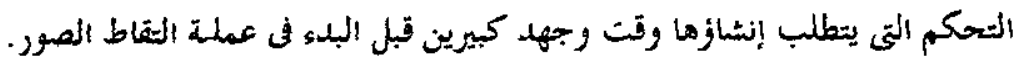

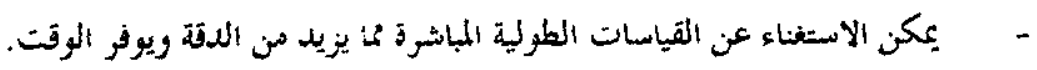

